\title{
MAINTENANCE OF THE COAL SAMPLE BANK AND DATABASE
}

\author{
Quarterly Technical Progress Report
}

Contract Number DE-AC22-93PC93051

The Pennsylvania State University

Coal and Organic Petrology Laboratories

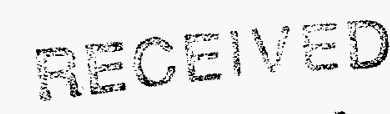

Aug 26 1956

OSTI

Reporting Period: 10/01/95 - 12/31/95

Report Date: 3/22/96

Contract Date: 9/28/93

Anticipated Completion Date: 9/28/98

Government Award: $\$ 156,000$. for current contract year

Principal Investigators: Alan Davis

David C. Glick

Program Manager: Gilbert V. McGurl

Contracting Officer's Representative: Udaya Rao

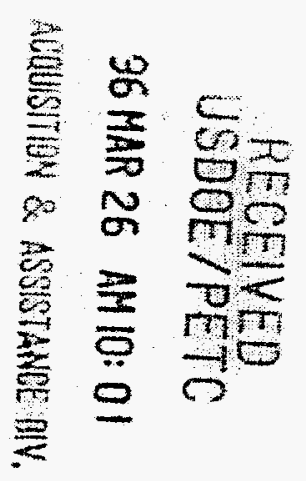

US/DOE Patent Clearance is not required prior to the publication of this document. 


\section{DISCLAIMER}

Portions of this document may be illegible in electronic image products. Images are produced from the best available original document. 
Quarterly Technical Progress Report: 10/01/95 - 12/31/95

Objectives:

This five year project is intended to ensure the availability of well-characterized, high-quality coal samples for public and private coal research. It continues support of the DOE Coal Sample Bank and Database at The Pennsylvania State University. Eleven coal samples will be collected, processed, packaged, and analyzed, and a resulting database will be maintained. These samples and data, as well as 45 samples collected under previous contracts, will be distributed to DOE contractors and others performing coal research.

Samples will be chosen to maintain a sample bank of 56 coals representing the major U.S. coal fields and a variety of coal ranks and compositions. In addition to standard analyses, liquefaction tests and organic geochemical analyses will be performed. The samples will be stored to minimize deterioration, and 10 samples will be monitored annually by proximate, sulfur forms, and gaseous oxygen analysis to evaluate their condition.

This report reflects the level of effort described in the revised work statement submitted to DOE on February 2,1996, setting out a reduction in effort following a cut in the level of funding of the project.

\section{Summary of Technical Progress}

Task 1B. Storage and Inventory of Samples

All samples supported by the contract are stored in containers purged with argon before sealing; container locations are tracked by a computer inventory program. PSOCseries samples are stored in drums or buckets at the Coal Sample Bank building, or in cans in the Coal and Organic Petrology Laboratories. All DECS-series samples are stored under refrigeration in foil laminate bags.

During the quarter, samples were distributed and inventory records were updated. Individual containers of splits of samples collected in recent quarters were added to the inventory records. Storage and inventory of sample containers is expected to continue routinely through the next quarter.

Task 1C. Monitoring of Sample Quality

It was planned that one $300 \mathrm{~g}(2 / 3 \mathrm{lb})$ bag of each DECS sample would be analyzed annually to monitor sample condition. This Task has been reduced in scope, to 10 samples per year, because of reduction in funding. The third annual monitoring program was begun at the end of the quarter. Two of the 10 samples were analyzed; both showed excellent preservation of their original properties.

The third annual monitoring program is scheduled for completion and reporting in the next quarter.

Effort in the related study of liquefaction behavior (under Task 1F) over time has also been reduced. 
Task 1D. Collection and Processing of Replacement Samples

Collection of 11 samples, as described in the Revised Statement of Work (Feb. 2, 1996) has been completed. During the quarter, standard processing of the last of these samples was completed.

Processing of earlier DECS samples to minus 60 mesh $(-0.25 \mathrm{~mm})$ will continue in succeeding quarters.

Task 1E. Basic Characterization of Coal Samples

All basic characterization of samples planned for collection under the contract has been completed.

Task 1F. Liquefaction Testing

In this Task, appropriate samples will be subjected to a standardized liquefaction test using tetralin and subsequent product workup.

Product workup was completed on four samples collected during the contract, as shown in Table 1.

Table 1. Conversion of DECS samples in a standardized liquefaction test using tetralin, with detailed gas composition (average of two runs, except gas components based on one run; see Task 1F).

\begin{tabular}{|c|c|c|c|c|c|c|c|c|c|c|c|c|}
\hline & \multicolumn{12}{|c|}{ conversion, percent of dry ash-free coal } \\
\hline \multirow{2}{*}{ sample } & \multirow{2}{*}{ total } & \multirow{2}{*}{ asph. } & \multirow{2}{*}{$\begin{array}{l}\text { pre- } \\
\text { asph. }\end{array}$} & \multirow{2}{*}{ oil } & \multicolumn{8}{|c|}{ gas } \\
\hline & & & & & total & $c 1$ & $\mathrm{c} 2$ & c3 & 04 & c5 & c1-c5 & other \\
\hline DECS-25 & 53.6 & 3.9 & 7.4 & 6.4 & 35.9 & 0.5 & 0.1 & & & & 0.6 & 35.3 \\
\hline DECS-26 & 54.6 & 5.3 & 10.1 & 6.8 & 32.4 & 0.5 & 0.1 & & & & 0.6 & 31.8 \\
\hline DECS-29 & 22.1 & 3.3 & 7.7 & 6.3 & 4.8 & 0.6 & 0.2 & 0.1 & & & 0.9 & 3.9 \\
\hline DECS-33 & 62.8 & 27.3 & 20.4 & 12.2 & 2.9 & 0.7 & 0.4 & 0.3 & 0.1 & & 1.5 & 1.4 \\
\hline
\end{tabular}

Task 1G. Investigation of Changes in Surface Chemistry During Storage This Task has been discontinued.

Task 1H. Organic Geochemistry

\section{Pyrolysis - Gas Chromatography - Mass Spectrometry}

Tables 2 and 3 summarize the composition of the pyrolysis products by type of compound for several samples collected during the contract. Table 2 shows results as percent of gc-amenable products; Table 3 normalizes these results to percent of 
identified products. In each table, results are preliminary; more peaks may be identified in the future. The Appendix shows the total ion chromatograms of the pyrolyzates produced from these samples.

Table 2. Structural parameters determined by py/gc/ms (percent of total gc-amenable products). Results of preliminary identification of peaks.

\begin{tabular}{|l|l|l|c|c|c|c|}
\hline sample & seam & rank & $\begin{array}{l}\text { n-alkanes } \\
\text { and } \\
\text { alkenes }\end{array}$ & phenols & $\begin{array}{l}\text { non-oxygenated } \\
\text { aromatic } \\
\text { hydrocarbons }\end{array}$ & $\begin{array}{l}\text { unident- } \\
\text { ified }\end{array}$ \\
\hline DECS-25 & Pust & ligA & 19.9 & 8.8 & 1.61 & 69.7 \\
\hline DECS-27 & Deadman & subA & 29.4 & 11.6 & 8.5 & 50.5 \\
\hline DECS-29 & Upper Banner \#3 & hvAb & 21.8 & 3.5 & 10.7 & 64.0 \\
\hline DECS-30 & Splash Dam & mvb & 28.0 & 3.6 & 4.3 & 64.1 \\
\hline DECS-31 & Pond Creek & hvAb & 17.9 & 15.4 & 4.5 & 62.2 \\
\hline DECS-32 & Stockton-Lewiston & hvAb & 15.3 & 20.1 & 10.3 & 53.5 \\
\hline
\end{tabular}

Table 3. Structural parameters determined by py/gc/ms (percent of identified products). Results of preliminary identification of peaks.

\begin{tabular}{|l|l|l|c|c|c|}
\hline sample & seam & rank & $\begin{array}{c}\text { n-alkanes } \\
\text { and } \\
\text { alkenes }\end{array}$ & phenols & $\begin{array}{l}\text { non-oxygenated } \\
\text { aromatic } \\
\text { hydrocarbons }\end{array}$ \\
\hline DECS-25 & Pust & lig & 65.7 & 29.0 & 5.3 \\
\hline DECS-27 & Deadman & subA & 59.4 & 23.4 & 17.2 \\
\hline DECS-29 & Upper Banner \#3 & hvAb & 60.6 & 9.7 & 29.7 \\
\hline DECS-30 & Splash Dam & mvb & 78.0 & 10.0 & 12.0 \\
\hline DECS-31 & Pond Creek & hvAb & 47.4 & 11.9 & 40.7 \\
\hline DECS-32 & Stockton-Lewiston & hvAb & 32.9 & 22.2 & 44.9 \\
\hline
\end{tabular}

Task 1I. Distribution of Coal Samples to Users

During the period 10/01/95 - 12/31/95 a total of 15 samples (13 DOE Sample Bank samples and 2 other Penn State samples) of various sizes in 31 containers were

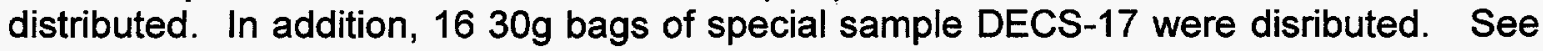
Task $2 \mathrm{C}$ for a list of sample and data recipients. This task will continue in the same manner through the next quarter.

Task 2A. Programming

No significant programming was undertaken during the quarter. 
Task 2B. Data Entry

Entry of basic characterization data for the 11 samples collected under the contract has been completed.

Task 2C. Distribution of Data to Users

During the quarter a total of 48 data printouts were distributed. In addition, 5 special data requests were filled by database searches and printed output or creation of a data disk, resulting in distribution of limited information on 235 samples. Preliminary requests for Sample Bank and Database information have been filled. This task will continue in the same manner through the next quarter.

Organizations supplied with coal samples and/or data include:

Indiana Geological Survey

Little Bear Laboratories

Nittany Geosciences, Inc.

Pennsylvania Department of Environmental Protection

Pennsylvania State University, Chemical Engineering Department

Pennsylvania State University, Geosciences Department

Pennsylvania State University, Office of Physical Plant, Steam Plant

Pennsylvania State University, Polymer Science Department

Pennsylvania State University, Mineral Processing Department

Pennsylvania State University, Fuel Science Department (2)

Southern Illinois University, Geology Department

University of Utah, Chemical and Fuels Engineering Department

West Virginia University, Chemical Engineering Department (2)

The numbers in parentheses represent multiple requests which were separately processed. 


\section{APPENDIX. Total ion chromatograms of pyrolyzates}

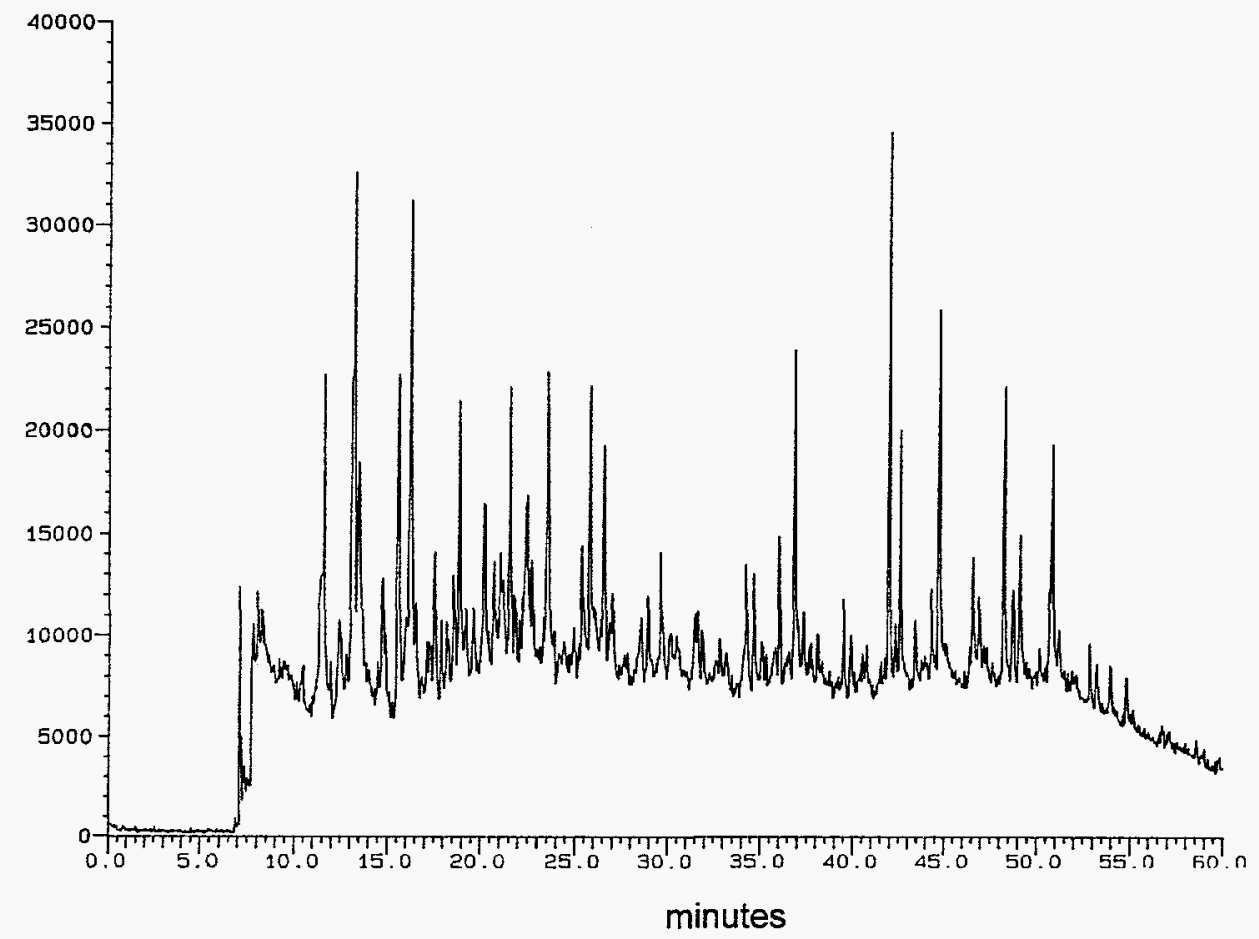

Figure 1. Total ion chromatogram of pyrolyzates from DECS-25, ligA Pust seam, MT.

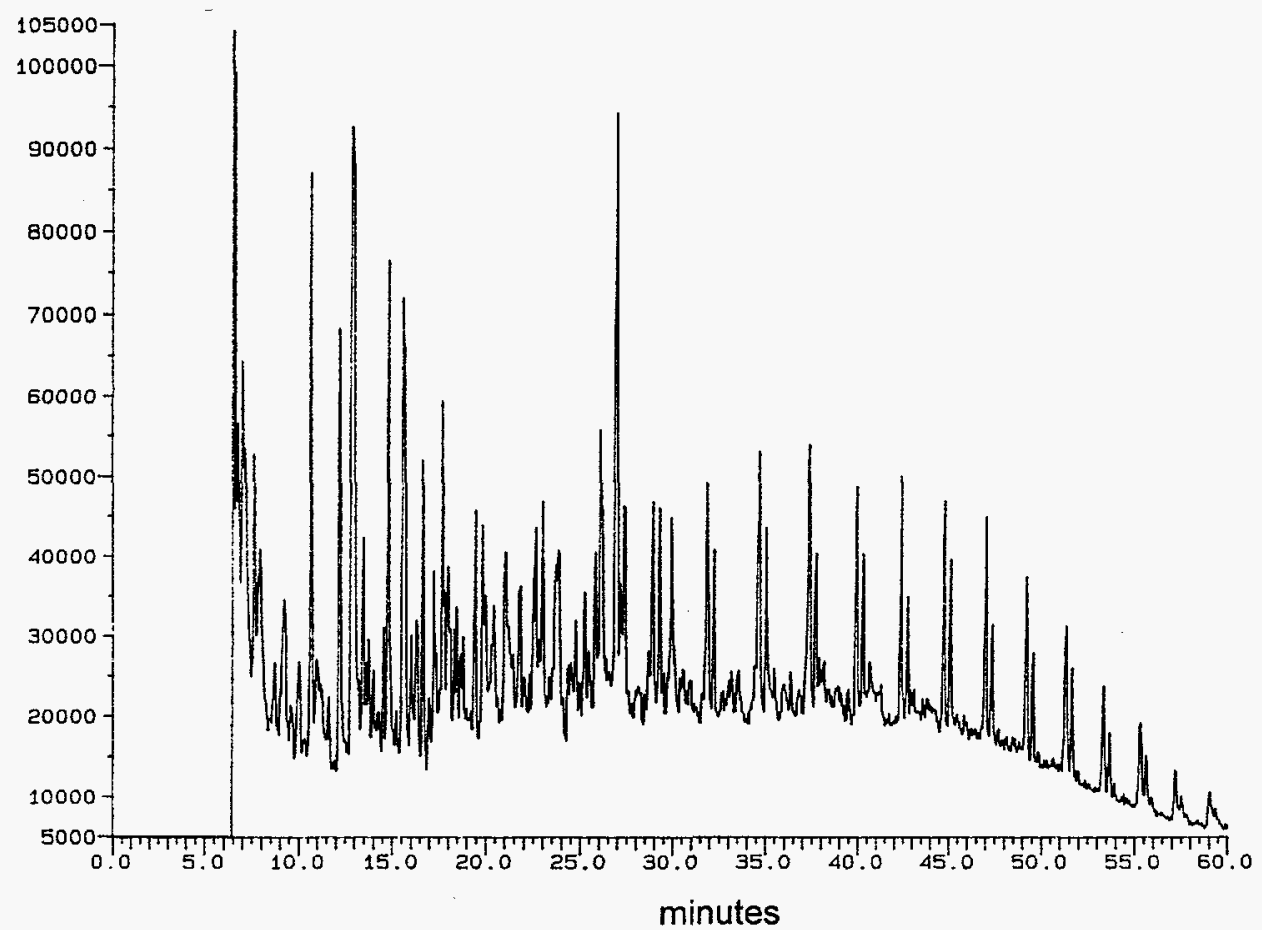

Figure 2. Total ion chromatogram of pyrolyzates from DECS-27, subA Deadman seam, WY. 
APPENDIX. Total ion chromatograms of pyrolyzates

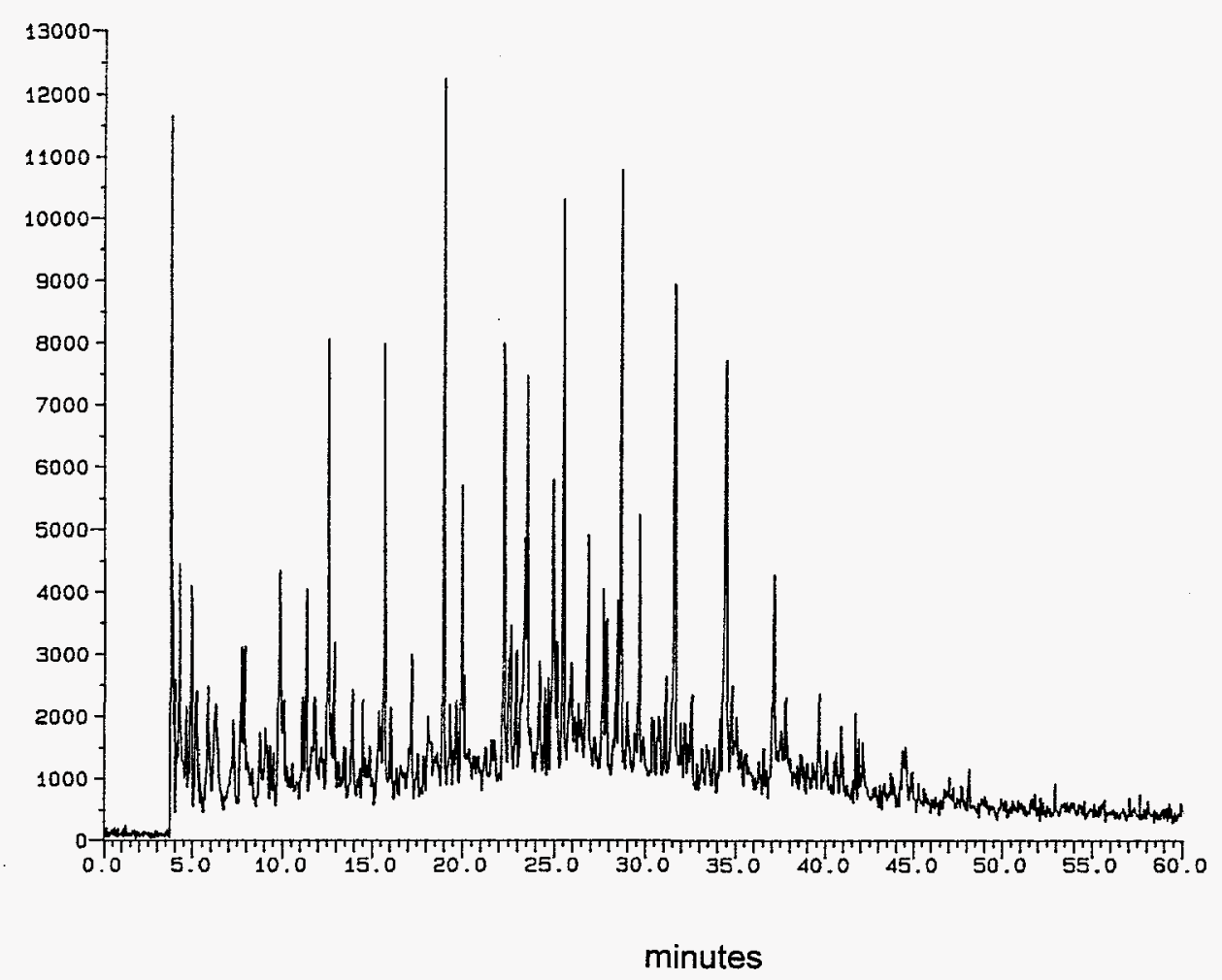

Figure 3. Total ion chromatogram of pyrolyzates from DECS-29, hvAb Upper Banner \#3 seam, VA.

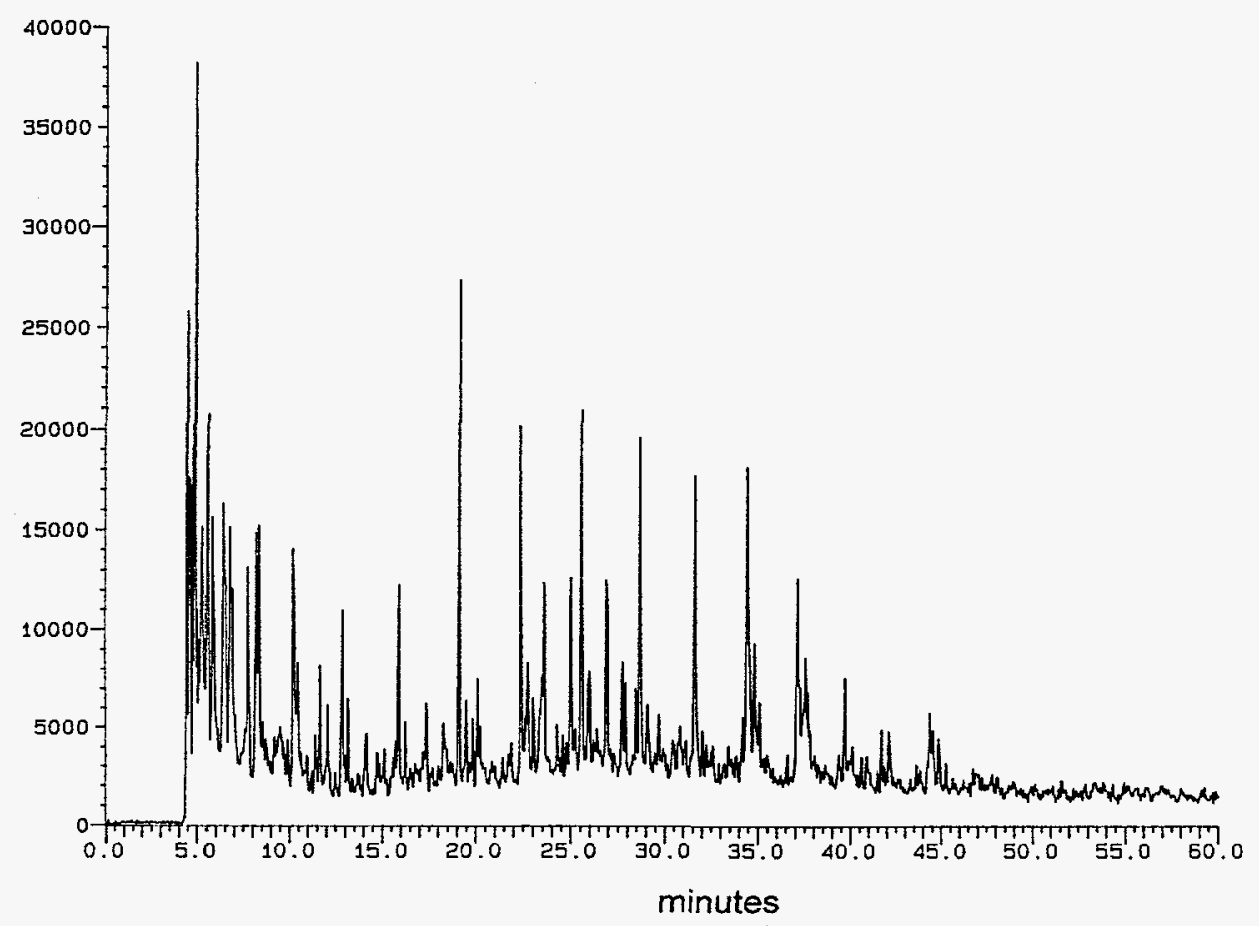

Figure 4. Total ion chromatogram of pyrolyzates from DECS-30, mvb Splash Dam seam, VA. 
APPENDIX. Total ion chromatograms of pyrolyzates

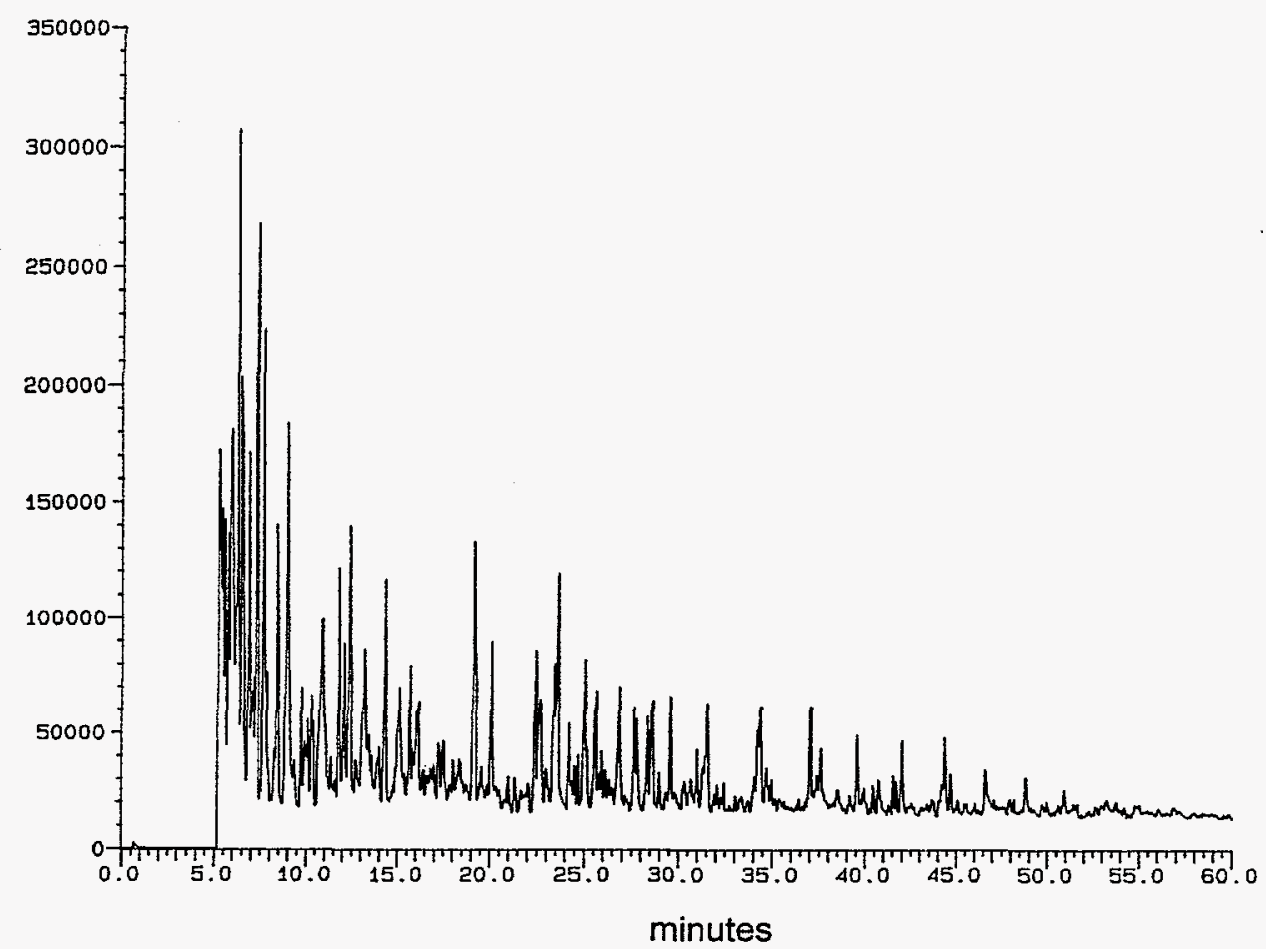

Figure 7. Total ion chromatogram of pyrolyzates from DECS-31, hvAb Pond Creek seam, KY.

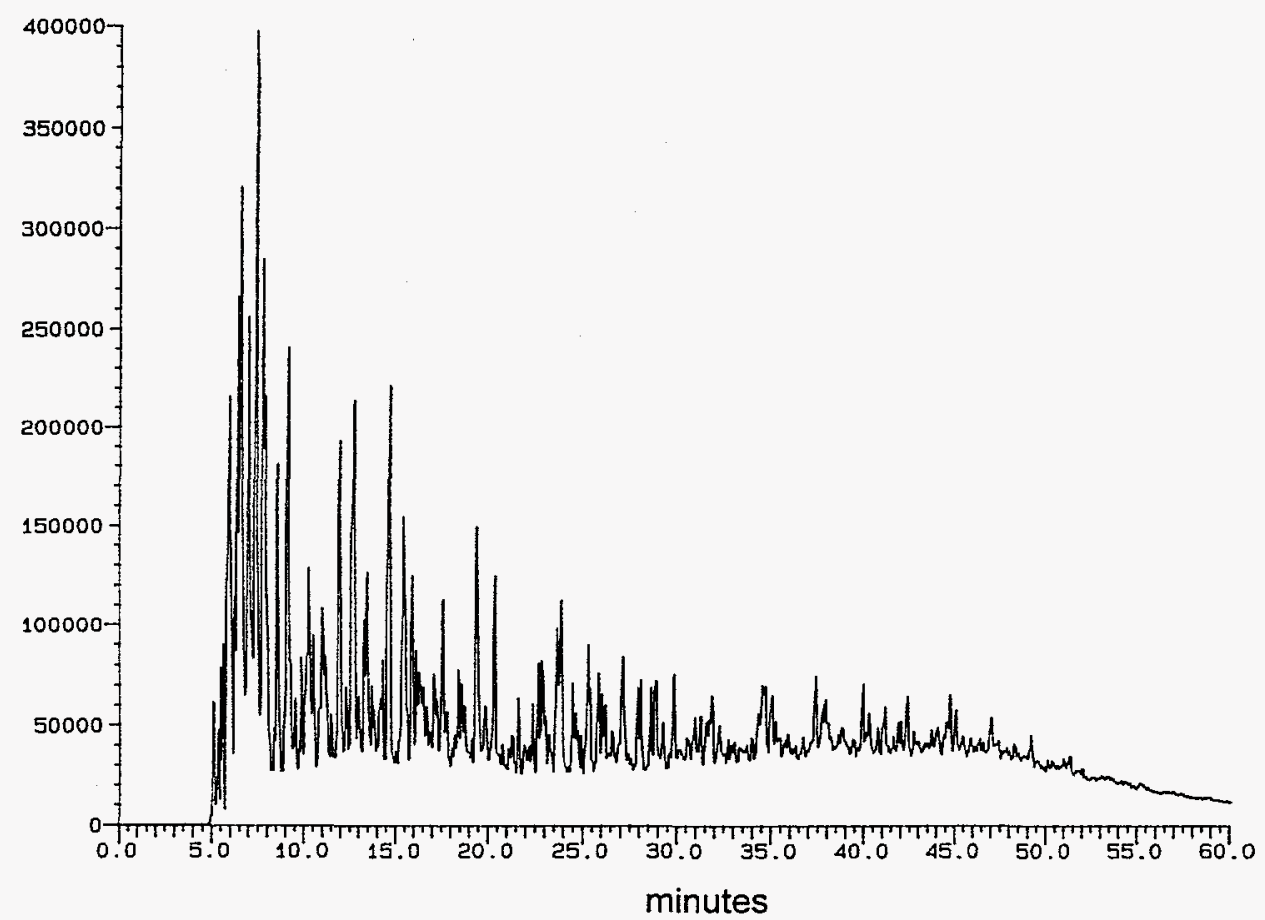

Figure 8. Total ion chromatogram of pyrolyzates from DECS-32, hvAb Stockton-Lewiston seam, $W V$ 


\section{DISCLAIMER}

This report was prepared as an account of work sponsored by an agency of the United States Government. Neither the United States Government nor any agency thereof, nor any of their employees, makes any warranty, express or implied, or assumes any legal liability or responsibility for the accuracy, completeness, or usefulness of any information, apparatus, product, or process disclosed, or represents that its use would not infringe privately owned rights. Reference herein to any specific commercial product, process, or service by trade name, trademark, manufacturer, or otherwise does not necessarily constitute or imply its endorsement, recommendation, or favoring by the United States Government or any agency thereof. The views and opinions of authors expressed herein do not necessarily state or reflect those of the United States Government or any agency thereof. 